\title{
Fabric Handle Equations for Australia, New Zealand, India and U.S.A.
}

\author{
By T. J. Mahar and R. Postle, Members, TMSJ
}

\author{
School of Textile Technology, The University of New South Wales, Kensington, N.S.W., 2033, Australia
}

Based on Journal of the Textile Machinery Society of Japan, Trasactions Vol. 37, No. 9, T143-T147 (1984-9)

\begin{abstract}
This paper presents a series of 10 equations for the translation of the Primary Hands ( $P H$ s) of men's suiting fabrics into Total Hand Values ( $T H V \mathrm{~s})$ according to the model used by Kawabata. These equations relate subjectively assessed $P H s$ to fabric handle assessments ( $T H V \mathrm{~s}$ ) of expert judges drawn from the textile and clothing industries of Australia, New Zealand, India and the U.S.A. for both winter weight and summer weight suiting fabrics. Results based on the handle preferences of a group of consumers drawn from the Australian market place are also included.

Users of the Kawabata Handle System should consider the market for which a fabric is manufactured when evaluating the handle of summer weight suiting fabrics as major differences were detected in the fabric handle preferences of some of the 5 national groups. There are also subtle differences in the fabric handle preferences of the expert judges for the winter weight fabrics.
\end{abstract}

\section{Introduction}

The Hand Evaluation and Standardization Committee of The Textile Machinery Society of Japan under the leadership of Professor S. Kawabata ${ }^{[1]}$ has successfully developed a system for the objective measurement of the fabric handle of both men's suiting fabrics and women's dress fabrics. The subjective assessments of fabric handle used as the basis for the specification of men's suiting material involved a range of 214 winter-weight and 156 summer-weight men's suiting fabrics which were assessed by a panel of 8 expert judges drawn from the Japanese weaving and finishing industries.

More recently, an international survey ${ }^{[2]}$ has been undertaken involving fabric handle assessments of these 2 sets of men's suiting fabrics by similar panels of expert judges drawn from the textile and clothing industries of Australia, New Zealand, India and the United States of America (U.S. A.). This international survey has been coordinated in New Zealand by Dr. G. Carnaby of the Wool Research Organization of New Zealand, in India by Professor V. B. Gupta of the Indian Institute of Technology and Dr. R. C. Dhingra of the University of New South Wales, in the U.S.A. by Dr. P. Brown of the University of Minnesota and in Australia by the present authors. The survey also included a panel of "consumers", or people with no textile expertise, drawn from the Australian marketplace.

Many interesting results concerning the agreement amongst the judges both within a country and between the various national groups have resulted from this study. ${ }^{[2]}$ This paper is concerned with the extension to countries outside Japan of Professor Kawabata's system for the objective measurement of the handle of men's suiting materials.

\section{Method}

Each of the expert judges was asked to assess for fabric handle small $(20 \mathrm{~cm} \times 10 \mathrm{~cm}$ ) samples of the 214 winter and 156 summer fabrics. In their assessments, the judges were requested to ignore the effect of fabric colour and pattern. The judges were asked to assess subjectively, without reference to standard samples, the handle of each fabric according to the rating scale given in Table 1 . Approximately 15 judges from each country completed the survey. The individual handle ratings of each judge were used to calculate the average handle assessment for each of the national panels of judges.

\begin{tabular}{c|l}
\hline \multicolumn{1}{c}{ Table 1 } & Total Hand Value \\
\hline$T H V$ & \multicolumn{1}{c}{ Evaluation } \\
\hline 5 & excellent \\
4 & good \\
3 & average \\
2 & below average \\
1 & poor \\
0 & out of use
\end{tabular}


Table 2 Fabric Primary Hand Values

\begin{tabular}{l|l}
\hline \hline Winter & Koshi \\
& Numeri \\
& Fukurami \\
\hline Summer & Koshi \\
& Shari \\
& Hari \\
& Fukurami \\
\hline
\end{tabular}

Each judge's individual rating was then correlated to the mean handle rating of his national group. The subgroup of 8 judges from each country who showed the highest correlation with their group mean rating was then selected as the panel of expert judges who best represent the fabric handle preferences of their country.

Besides the fabric handle ratings previously discussed, each of these fabrics was subjectively rated by the Japanese panel for the various primary hand expressions, or fabric characteristics, quoted by Kawabata ${ }^{[1]}$ as being the important primary components of fabric handle. These primary components, which are given in Table 2, are "Koshi" (stiffness), "Numeri" (smoothness) and "Fukurami" (softness and fullness) for the winter fabrics; and "Koshi" (stiffness), "Shari" (crispness), "Hari" (anti-drape stiffness) and "Fukurami" (softness and fullness) for the summer fabrics.

\section{Results and Discussion}

The primary hand ratings of the Japanese panel of judges have been used to predict the group mean handle ratings of each of the national panels of expert judges. The calculations followed the procedure adopted in the model proposed by Kawabata ${ }^{[1]}$ to predict the handle preferences or Total Hand Values, of the Japanese panel of expert judges.

The general form of the mathematical model used to predict Japaneses preferences for fabric handle is: Handle rating (or Total Hand Value, $T H V$ )

$$
\begin{aligned}
& =C_{0}+\sum_{i=1}^{k} Z_{i} \\
Z_{i} & =C_{\imath_{1}}\left(\frac{Y_{i}-M_{i_{1}}}{\sigma_{i_{1}}}\right)+C_{t_{2}}\left(\frac{Y_{i}^{2}-M_{i_{2}}}{\sigma_{t_{2}}}\right)
\end{aligned}
$$

$Y_{i}$ : handle characteristics given in Table 2

$M_{i 1}, M_{i 2}, \sigma_{i 1}, \sigma_{i 2}$ : mean value of $Y$ and $Y^{2}$ and standard deviation of $Y$ and $Y^{2}$ respectively (see Appendix 1 for values of $M_{i 1}, M_{i 2}, \sigma_{i 1}$ and $\sigma_{i 2}$ )

$C_{0}, C_{i 1}, C_{i 2}$ : constants.

The values for the constants used in the model to determine the contribution to total hand value of the primary hand expressions have been published by Kawabata ${ }^{[1]}$ for the case of the Japanese panel of expert judges. These values and the corresponding values for the non-Japanese expert and consumer sub-group panels of 8 judges are given in Tables 3 and 4 for the winter and summer fabrics, respectively. The values of these constants were calculated with the

Table 3 Constants and Multiple Correlation Coefficients for the Winter Fabric $H V-T H V$ Translation Equa-

\begin{tabular}{|c|c|c|c|c|c|}
\hline \multirow{2}{*}{$\begin{array}{l}\text { Constants } \\
\text { for } \\
\text { each } \\
\text { Judging } \\
\text { Panel }\end{array}$} & \multicolumn{3}{|c|}{$\begin{array}{l}\text { Winter Primary Hand Expressions } \\
\qquad(P H)\end{array}$} & \multirow{2}{*}{$\begin{array}{l}\text { Multiple } \\
\text { Correla- } \\
\text { tion } \\
\text { Coeffic- } \\
\text { ient }\end{array}$} & \multirow[b]{2}{*}{$C_{0}$} \\
\hline & $\begin{array}{c}\text { Stiff- } \\
\text { ness } \\
(K o s h i)\end{array}$ & $\begin{array}{l}\text { Smooth- } \\
\text { ness } \\
(\text { Numeri) }\end{array}$ & $\begin{array}{c}\text { Softness and } \\
\text { Fullness } \\
(\text { Fukurami })\end{array}$ & & \\
\hline \multicolumn{6}{|l|}{ Japanese: } \\
\hline$C_{1}(P H)$ & 0.6750 & -0.1887 & 0.9312 & 0.90 & 3.1466 \\
\hline$C_{2}(P H)^{2}$ & -0.5341 & 0.8041 & -0.7703 & & \\
\hline \multicolumn{6}{|l|}{ Australian: } \\
\hline$C_{1}(P H)$ & 0.3810 & 1.2622 & -0.0376 & 0.94 & 2.7768 \\
\hline$C_{2}(P H)^{2}$ & -0.3282 & -0.1429 & -0.0282 & & \\
\hline \multicolumn{6}{|c|}{ New Zealand: } \\
\hline$C_{1}(P H)$ & 0.4620 & 1.3449 & -0.1562 & 0.86 & 3.1449 \\
\hline$C_{2}(P H)^{2}$ & -0.3644 & -0.7663 & 0.2011 & & \\
\hline \multicolumn{6}{|l|}{ Indian : } \\
\hline$C_{1}(P H)$ & 0.7091 & 1.2617 & -0.4972 & 0.88 & 3.0380 \\
\hline$C_{2}(P H)^{2}$ & -0.6818 & -0.2446 & 0.3467 & & \\
\hline \multicolumn{6}{|c|}{ United States: } \\
\hline$C_{1}(P H)$ & 0.4146 & 1.4450 & -0.2489 & 0.85 & 3.1351 \\
\hline$C_{2}(P H)^{2}$ & -0.4842 & -0.6288 & 0.1343 & & \\
\hline \multicolumn{6}{|l|}{ Consumer: } \\
\hline$C_{1}(P H)$ & 1.2271 & 1.1203 & 0.4430 & 0.83 & 3.1483 \\
\hline$C_{2}(P H)^{2}$ & -0.9793 & -0.4196 & -0.3986 & & \\
\hline
\end{tabular}
tions for each National Judging Panel. 
Table 4 Constants and Multiple Correlation Coefficients for the Summer Fabric $H V-T H V$ Translation Equations for each National Judging Panel.

\begin{tabular}{|c|c|c|c|c|c|c|}
\hline \multirow{2}{*}{$\begin{array}{l}\text { Constants } \\
\text { for } \\
\text { each } \\
\text { Judging } \\
\text { Panel }\end{array}$} & \multicolumn{4}{|c|}{ Primary Hand Expressions $(P H)$} & \multirow{2}{*}{$\begin{array}{l}\text { Multiple } \\
\text { Correla- } \\
\text { tion } \\
\text { Coeffi- } \\
\text { cient }\end{array}$} & \multirow[b]{2}{*}{$C_{0}$} \\
\hline & $\begin{array}{l}\text { Stiff- } \\
\text { ness } \\
(K o s h i)\end{array}$ & $\begin{array}{l}\text { Crisp- } \\
\text { ness } \\
(\text { Shari) }\end{array}$ & $\begin{array}{c}\text { Anti-drape } \\
\text { Stiff ness } \\
\quad(\text { Har } i)\end{array}$ & $\begin{array}{c}\text { Softness and } \\
\text { Fullness } \\
(\text { Fukurami })\end{array}$ & & \\
\hline \multicolumn{7}{|l|}{ Japanese : } \\
\hline$C_{1}(P H)$ & -0.0004 & 1.1368 & 0.3316 & 0.5309 & 0.85 & 3.2146 \\
\hline$C_{2}(P H)^{2}$ & 0.0066 & -0.5395 & -0.4977 & -0.3741 & & \\
\hline \multicolumn{7}{|l|}{ Australian: } \\
\hline$C_{1}(P H)$ & -1.0332 & -0.0542 & 1.0779 & 0.7032 & 0.83 & 2.5073 \\
\hline$C_{2}(P H)^{2}$ & 0.8994 & -0.3176 & -1.2219 & -0.6992 & & \\
\hline \multicolumn{7}{|l|}{ New Zealand: } \\
\hline$C_{1}(P H)$ & -0.7082 & 0.2432 & 0.9902 & 0.4482 & 0.83 & 3.0825 \\
\hline$C_{2}(P H)^{2}$ & 0.7945 & -0.6296 & -1.1357 & -0.3373 & & \\
\hline \multicolumn{7}{|l|}{ Indian : } \\
\hline$C_{1}(P H)$ & -0.3644 & 0.1152 & 0.1585 & -0.0560 & 0.81 & 2.6489 \\
\hline$C_{2}(P H)^{2}$ & 0.3135 & -0.4730 & -0.4308 & -0.0982 & & \\
\hline \multicolumn{7}{|l|}{ United States: } \\
\hline$C_{1}(P H)$ & -0.2250 & -0.0460 & 0.5740 & 0.3452 & 0.70 & 2.8281 \\
\hline$C_{2}(P H)^{2}$ & 0.2471 & -0.3679 & -0.7720 & -0.4494 & & \\
\hline \multicolumn{7}{|l|}{ Consumer: } \\
\hline$C_{1}(P H)$ & -0.9173 & 0.8220 & 0.6741 & 0.5958 & 0.79 & 3.1482 \\
\hline$C_{2}(P H)^{2}$ & 0.7430 & -1.1430 & -0.8095 & -0.6638 & & \\
\hline
\end{tabular}

aid of a standard multiple linear regression technique ${ }^{[3]}$ using the fabric handle ratings obtained in the international survey.

The values of the multiple correlation coefficients in Tables 3 and 4 with the exception of the U.S. summer fabric assessments are high, ranging from 0.79 for the consumer summer fabric ratings to 0.94 for the Australian winter fabric ratings. High multiple correlation coefficients indicate that the model based on Japanese subjective assessments of the primary hand expressions can be used to predict the fabric handle preferences of the non-Japanese panels of expert and consumer judges to the level of accuracy applicable to the Japanese expert panel. In the case of the U.S. summer fabric assessments the lower value of the multiple correlation coefficient $(0.70)$ indicates less reliablility when the Japanese model is applied. This effect may be related to the dominance of synthetic and cellulosic fibres in the men's suit market in the U.S., particularly for summer fabrics. For the present international survey of fabric handle, the fabrics had been collected in Japan and are predominately pure wool and wool/synthetic materials. ${ }^{[2]}$ The results shown in Table 4 indicate that, in order to achieve a higher level of reliability of prediction for U.S. summer fabric handle, another Primary Hand expression (derived from lightweight synthetic and cellulosic materials) may be required.

The fabric handle preferences for the various judging panels are very similar for the winter fabrics. This similarity has been analysed by the present authors in some detail elsewhere ${ }^{[2]}$ and the results of a statistical factor analysis for the expert judgements of winter fabric handle is now in publication. ${ }^{[4]}$ The similarity in winter-fabric handle preferences among national judging panels is difficult to detect from ex- amination of the values of the constants given in Table 3 because of the obviously high correlations between the value of a $P H$ (primary hand expression) and its square $P H^{2}$, and also because of the high correlation $(0.90)$ between "Numeri" (fabric smoothness) and "Fukurami" (fabric softness and fullness). The average handle rating for each national panel of the full set of 214 winter fabrics, given by the value of the constant, $C_{0}$ falls within a relatively narrow band, ranging from 2.78 for the Australian expert panel to 3.15 for the Japanese expert and Australian consumer panels. This result indicates that all panels had a similar average level of appreciation for the hand of the winter fabrics.

For the summer fabrics, it has been shown ${ }^{[2]}$ that although there is a good level of agreement among the non-Japanese panels of judges, there is a marked tendency for disagreement between the Japanese and each of the other national panels of judges. The Japanese judges show significant positive correlation coefficients ${ }^{[2]}$ with Koshi $(0.51)$, Shari $(0.74)$ and Hari (0.43) whereas all the other judging panels show significant negative values for the correlation coefficients with these three summer fabric Primary Hand expressions (ranging from -0.52 to -0.75 ). Although there is a strong interaction between the three Japanese summer fabric Primary Hand expressions of Koshi, Shari and Hari, the negative correlation coefficients for the non-Japanese judging panels is greatest for the case of Shari. The difference in summer fabric handle expressions can be seen by inspection of Table 4 where the Japanese preference for a crisp summer fabric handle shows in the positive net contribution (i.e., the sum of the contribution to $T H V$ of the linear and squared terms for each of the Primary Hand expressions) of the constants for 
Shari $P H$ and $P H^{2}$. The dislike shown for a very crisp fabric handle by each of the non-Japanese panels of judges is evidenced by the negative net contribution to summer fabric THV of the constants for Shari $\mathrm{PH}$ and $\mathrm{PH}^{2}$. For the summer fabrics, the average handle ratings for each of the panels of judges ranged from 2.51 for the Australian expert panel to 3.21 for the Japanese panel. This result indicates a wider spread in the judges' overall appreciation of the summer fabrics than for the winter fabrics.

\section{Conclusion}

A system for the objective specification of fabric handle preferences for the Japanese textile and clothing industries has been developed by Kawabata et al. ${ }^{[1,5]}$ An international survey of the fabric handle preferences of judges drawn from the textile and clothing industries of Australia, New Zealand, India and the U.S.A. has provided the necessary data for a similar system of fabric handle specification in these countries. The separate specification of fabric handle on a national basis is necessary because, though there is broad overall agreement amongst the international panels of judges about winter fabric handle, there are subtle differences in handle preferences amongst the various national judging panels. ${ }^{[4]}$ These differences suggest that users of Kawabata's system for the objective measurement of fabric handle should consider the market for which a fabric is manufactured when evaluating the handle of winter-weight suiting fabrics.

Because of the much more readily defined differences in handle expectations between the Japanese and non-Japanese panels of judges when assessing summer fabric handle, it is imperative that users of this fabric handle specification system relate their measurements to the relevant national market when assessing the handle of summer-weight suiting fabrics.

The values for the constants of the Kawabata handle specification equations given in this paper for the Australian, New Zealand, Indian and U.S. markets will enable users of these equations to specify fabric handle for these markets in a more confident manner. The fabric handle survey is now being extended to the European markets of Germany and Italy. The applicability of the Kawabata equations in these markets will also be investigated.

\section{Acknowledgements}

The authors are greatly indebted to the many judges whose contributions of time and expertise made this work possible. They also wish to acknowledge the technical support of Mr. J. Galea. The extensive cooperation of Professor S. Kawabata of Kyoto University (Japan), Professor M. Niwa of Nara Women's University (Japan), Dr. G. Carnaby of the Wool Research Organization of New Zealand, Professor V. B. Gupta of the Indian Institute of Technology and Dr. Brown of the University of Minnesota (U.S.A.) is gratefully acknowledged and much appreciated.

\section{References}

[1] S. Kawabata; "The Standardization and Analysis of Hand Evaluation", 2nd edition, The Textile Machinery Society of Japan, Osaka, 1980.

[2] R. C. Dhingra, T. J. Mahar, R. Postle, V. B. Gupta, S. Kawabata, M. Niwa and G. A. Carnaby; "The Objective Specification of the Handle of Men's Suiting Materials; A Comparison of Fabric Handle Assessments in India, Australia, Japan and New Zealand", Indian Journal of Textile Research, 8, March, 1983.

[3] N. R. Draper and H. Smith; "Applied Regression Analysis", John Wiley and Sons, 1966.

[4] A. E. Stearn, R. D'Arcy, T. J. Mahar and R. Postle; J. Text. Mach. Soc. Japan, 38, T157 (1985).

[5] S. Kawabata; (Chairman) Hand Evaluation and Standardization Committee, "Standard of Hand Evaluation", Volume 3, The Textile Machinery Society of Japan, Osaka, 1982.

\section{Appendix 1}

Values of the means and standard deviations for each of the $P H$ and $P H^{2}$ defined by Kawabata" as being necessary for the objective specification of fabric handle for 214 winter and 156 summer fabrics.

\begin{tabular}{c|c|c|c|c}
\hline \hline & $M_{i 1}$ & $M_{i 2}$ & $\sigma_{i 1}$ & $\sigma_{i 2}$ \\
\hline (a) Winter fabrics & & & & \\
$i=1:$ Kosh $i$ & 5.7093 & 33.9032 & 1.1434 & 12.1127 \\
$i=2:$ Numer $i$ & 4.7537 & 25.0295 & 1.5594 & 15.5621 \\
$i=3:$ Fukurami & 4.9798 & 26.9720 & 1.4741 & 15.2341 \\
\hline (b) Summer fabrics & & & & \\
$i=1:$ Koshi & 4.6089 & 22.4220 & 1.0860 & 11.1468 \\
$i=2:$ Shari & 4.7480 & 24.8412 & 1.5156 & 14.9493 \\
$i=3:$ Fukurami & 4.9217 & 25.2704 & 1.0230 & 10.1442 \\
$i=4:$ Hari & 5.3929 & 30.7671 & 1.2975 & 14.1273 \\
\hline
\end{tabular}

